\title{
MEDIATION OF TRANSFER MOTIVATION ON THE RELATIONSHIP BETWEEN SUPERVISOR SUPPORT, PEER SUPPORT AND TRANSFER OF TRAINING
}

\author{
Wasilu Suleiman* \\ Bauchi State University-Gadau \\ Mudiyanselage Saman Dassanayake \\ University of Colombo \\ Abang Ekhsan Abang Othman \\ Universiti Malaysia Sarawak
}

\begin{abstract}
This paper investigated the mediation role of transfer motivation on supervisor and peers' support in transferring training on the population of teachers. The constantly changing attitude of employees towards job has negatively affected the traditional employment engagement that offers an employee a sense of social support from supervisors and peers in their jobs. Thus, the emergence of additional several new training transfer variables from the studied data indicates that the existing training transfer models can be modified further. Hence, the hypotheses of this study are formulated. Survey design method and simple random sampling technique were utilized. Additionally, data is collected through survey questionnaire on the basis of 5-points Likert scale. An aggregate of 605 copies of the questionnaire were finally retained for analysis. Smart-PLS measurement and structural model were the procedures employed to assess and evaluate the statistical significance of relevant path coefficients. The findings showed that the extent to which employees are provided with social support in their jobs would drive them to be desirous in making persistent and intense efforts towards utilizing skills and knowledge learned in the work settings. Also, this study highlighted that transfer motivation is a key element in the transfer of training processes.
\end{abstract}

Keywords: Peer Support; Supervisor Support; Transfer of Training; Transfer Motivation; Nigeria.

\section{INTRODUCTION}

In the present days, training programs are conceived by organizations not only as an investment that improves capabilities and competencies of employees to perform better in their jobs, but also as a tool which connect the effectiveness of job performance and behaviors (Burke \& Hutchins, 2007; Guerrazzi, 2016; Van der locht, Van Dam, \& Chiaburu, 2013). Effective training programs can affect the workers' attitudes and behavior; it indicates that what they have learnt during the training session has positively impacted on the organizational aims and objectives. Abdullah (2009) claimed that for an organization to value the system of training its outcome status must be elevated. Ripley (2002) supported the argument by stressing that effective training can be able to be transferred on the workers attitude and behavior in implementing their jobs. Yet, the results of different past studies have revealed that the expected amount of transfer of knowledge, skills and attitudes has not been reasonably occurring (Facteau, Dobbins, Russell, Ladd, \& Kudisch, 1995; Raliphada, Coetzee, \& Ukpere, 2014).

\footnotetext{
-Department of Business Administration, Bauchi State University-Gadau, Bauchi State, Nigeria; +2348066931068;
} wasilusuleiman@yahoo.com 
Training is regarded as effective if the investment made could be justified and skills and knowledge learned during the training can be applied and transferred to the workplace (Bjerregaard, Haslam, \& Morton, 2016). Unlike the physical and financial investment, investment in training brings unique advantages to organizations due to the fact that training upgrades organizational performance (Nikandrou, Brinia, \& Bereri, 2009). This is achievable through expanding the employees' motivation, skills, and learning (Bulut \& Culha, 2010). Despite considerable criticality and sum of money used on training, there are confirmations that transfer of training knowledge is frequently missing (Danielson \& Wiggenhorn, 2003). Training transfer has been comprehensively adopted as one of the important elements which builds employee performance and gains higher return on investment for organization in reciprocity (Hua \& Ahmad, 2011). Transfer of training shall therefore be seen as vitally significant for training programs to be efficient and effective. Besides, the expected return on investments in training programs will only be realized when reasonable amount of training is transferred (Nijman et al., 2006; Thory, 2016). Training of transfer takes place when the trainee exits training venue and applies what he or she has acquired directly or indirectly through the support of either supervisor or peers (Nikandrou et al., 2009).

\subsection{Supervisor Support}

Supervisor support is viewed as the degree to which managers or supervisors reinforce and support the use of training programs at the workplace (Holton \& Bates, 2000). The support from the supervisor has been found to be among the variables that correlate with training transfer (Lancaster, DiMilia, \& Cameron, 2013). Supervisory support and encouragement can include the general view of employee capacity development as a distinct aspect of the supervisors and managers' jobs coupled with more practical and immediate aspects, such as providing the skills practice time for the employees and offering reminders for implementations of the skills (Chiaburu \& Lindsay, 2008). That is, the capacity of the supervisor to give support, for example, encouragement to go to training, direction on the best way to apply training skills and knowledge, and sufficient time and opportunities to apply training had the ability to motivate employees to apply training program onto the job (Wei, Cordery, \& Gamble, 2016). However, supervisors have frequently cantered on recognizing short-term and daily skills deficiencies in performing their daily jobs and reporting employees' problems to the top management; the unsupported employee keeps on repeating old practices (Adair, 1988). Hence, the supervisors and employees come to view training program as a waste of time (Sverke \& Hellgren, 2002). Research has shown that when employees got reasonable amount of support from supervisors then they got clearer direction, more chances, and satisfactory time to comprehend how to make best utilization of the training program in their working environment. This, thus, brought about better job attitudes and performance (Petty, Lim, \& Zulauf, 2003).

\subsection{Peer Support}

Peer support reflects the level to which peers' behavior produces support and reinforcement for trainee's transfer of training (Nijman et al., 2006). Danielson and Wiggenhorn (2003) noted that peers can prevent or promote job performance and training transfer. Employees perform their daily jobs in an interactive setting or right climate, the influence of employee's co-workers on training transfer may be stronger than the one originating from the organization and supervisors accurately because of the consistent influx of information and other basic resources starting from the peers side (Van der locht et al., 2013). Furthermore, Jarvis, Holford, and Griffin (2006) found that individual learning is always situated within the work context. Therefore, it affects human relationships and shared interpretations. Training as an individual way of learning is encouraging opportunity for organizations and employees to acquire new information by experiencing and observing things around their environment (Howardson \& Behrend, 
2015). To interpret this, the acquired knowledge and information shall be reflecting the individual development, shared mental models, experiences, and transferring these acquired concepts into the work contexts (Ling, Woon, \& Ven, 2006). Massman (2012) pointed out that peers are possible supporters for employees in attaining opportunities to apply the trained knowledge. Consequently, peers can provide the appropriate support for transfer of training (Massman, 2012). Support from colleagues and peers have also proven to yield consistent influence on employee training transfer (Facteau et al., 1995). Thus, peers could receive training as potential coaches by giving them some checklist to periodically evaluate the performance of their fellow colleagues.

\subsection{Transfer Motivation}

Transfer motivation has been a broadly concentrated variable that helps better understand the training transfer (Combs, Luthans, \& Griffith, 2009). In view of that, transfer motivation is said to be predicted by work environment characteristics (Noe, 1986). In this field of study past authors accept a satisfactory understanding of this factor will help the application of the new learned knowledge in the workplace (Aguinis, \& Kraiger, 2009). The trainee expectations and perceptions will be higher when they experience motivational elements (Van der Locht et al., 2013). For this reason, transfer motivation was among key variables in determining the extent of transfer of training. Therefore, improving employees training transfer motivation is fundamental to success of training transfer (Kirwan \& Birchall, 2006). Concentrating on the effectiveness of training, transfer motivation is expected to influence the trainee interest for transfer of training, the direction of employees to master and learn the training program (steering) and the utilization of knowledge and skills at workplace (support) (Moldjord \& Hybertsen, 2015). There is no doubt that trainee abilities and trainee transfer motivation are determinants of effectiveness of training programs (Noe, 1986), hence, the basic principles of the transfer motivational approach is that jobs will be fully enriched, i.e. made employees' job to be more motivating and satisfying. If high levels of these characteristics are present, then the organizational goals and objectives could be realized (Bhatti \& Hoe, 2012). Transfer motivation is mostly considered to be effective by trainee perceptions of the relevance or irrelevance of the organized training program and their perceptions of having opportunities to transfer learning on the job (Foxon, 1997). It is also an individual employee transfer motivation that influences the practice and the use of newly trained knowledge even in the presence lack of reinforcement and of criticism (Noe \& Schmitt, 1986). Thus, it could be difficult to effectively transfer learning without motivational elements (Chiou, Lee, \& Purnomo, 2010).

This study, however, draws its theoretical based upon the review of social cognitive learning theory and Baldwin and Ford's model which is concerned with the functions of human beings as a whole in their different work activities, though has some limited implication for training transfer strategies. Since much of the transfer of training activities actually consists of modeling. Work environment factors are imperative for transfer of training (Burke \& Hutchins, 2007), although, they are not fully and sufficiently analyzed in existing training transfer models. Additionally, it is recommended that future studies shall incorporate the role of transfer motivation within the relationship between work environment variables and other training outcomes (Chang \& Chiang, 2011). Researchers have based their studies on specific indicator factors (Hua \& Ahmad, 2011; Mani, John, Ping, \& Ismail, 2006), but only a few of them have addressed the perceived motivational support arising from the supervisors and peers in connection with transfer of training. Transfer of training may be understood as at least partially a function of the motivational component associated with employees' personal job attitudes (Suleiman, Dassanayake, \& Othman, 2015). Employees at times fail to meet their expected support and encouragement for improved performance level due to unforeseen circumstances. When employees perceive that their job is not supported, they do not perform in the manner and behavior that may result in the utilization of the knowledge and skills learned for the organization (Jehanzeb, Rasheed \& Rashees, 2013). Therefore, 
relationships between transfer motivation and other work environment factors are unknown. Additionally, human resource practitioners have less or little information and awareness about the selected factors of work environment in employees' transfer motivation of knowledge and skills learned from the training program. Based on these reasons, there is a dearth of research on what inspires employees to transfer the learned knowledge to their daily jobs. The emergence of additional several new training transfer variables from the studied data indicates that the existing training transfer models can be modified further. Hence, the hypotheses of this study are formulated. The researchers found it obliged to further uncover the mediating role of transfer motivation in the relationship between supervisor support, peer support and transfer of training.

\section{$H_{a} 1$ : Transfer Motivation mediates the effect of Supervisor Support on Transfer of Training}

$H_{a} 2$ : Transfer Motivation mediates the effect of Peer Support on Transfer of Training

\section{RESEARCH METHODS}

The survey design method offers more reliable techniques for examining the information gathered about the sample of the study. It also enables the researcher to generalize and draw meaningful conclusions about the research findings on the entire population of the study (Creswell, 2008). The sampling technique that was used in collecting data via a questionnaire is simple random sampling on the entire selected respondents from the population. To this effect, the minimum sample size for this study is three hundred and seventy nine (379) (Krejcie \& Morgan, 1970). Additionally, this study employed a survey questionnaire for collecting data on the basis of 5-points Likert scale. The items on the questionnaire were adapted, adopted, and modified through readings of related literature and scales. Adaptation and adoption of research instrument are necessary because the population of this study differs from the original research population with which the items of the questionnaire were developed or used in respect to country, culture, and language (Davis, 1996). A number of items were used in measuring the employees' perception. For example, my supervisor sets objectives to help me improve my skills after the training program ends, my co-workers encourage me to attend the training program, the knowledge and skills I learned in the training program will be helpful in solving my work-related problems and after attending a training program my work performance has improved. Hence, this research provides the statistical explanation, description and relationships among the research variables. The location of this study is employees of Universal Basic Education Board, Bauchi State, Nigeria. An aggregate of 1,000 copies of the questionnaire was distributed to the respondents in an Education Board in Nigeria. Nevertheless, only 605 copies of the questionnaire were finally retained for analysis. The simple random sampling was used in this study for collecting data. The items on the questionnaire were adapted, adopted and modified through readings of related literature and scales (Akinbobola, 2011; Kanungo, 1982; Kirwan \& Birchall, 2006). The data from the questionnaire was analyzed through the use of Structural Equation Model-Partial Least Square (Smart-PLS) to test the formulated research hypotheses and analyze the collected data.

\section{FINDINGS}

The present study adopted the recommended two-step as measurement model and structural model in assessing the path results of PLS-SEM (Henseler \& Sarstedt, 2013). The measurement model was examined through convergent and discriminant validity (Sekaran \& Bougie, 2010). The validity of a certain statistical measurement scale is convergent when values are $>0.7,>0.7$, and $>0.5$ for loadings, 
composite reliability, and average variance extracted, respectively (Barclay, Higgins, \& Thompson, 1995). In this study, all items that exceeded the recommended threshold values for loadings, average variance extracted and composite reliability were retained whereas those with lower values were eliminated. For discriminant validity, calculated square roots for the coefficient of AVE are displayed in the diagonal axis within the correlation matrix. To achieve good discriminant validity, however, the squared AVE value should be higher than correlation estimates (Hair et al., 2006). Consequently, all the calculated AVE square roots for the constructs under study are greater than the diagonal elements in the corresponding columns and rows. Hence, the discriminant validity is established. However, the structural model was assessed through the use of bootstrapping technique for testing the significance of all the path coefficients because in PLS analysis, bootstrapping is the only mechanism for examining the significance of path coefficients (Chin, 2010). Table 1 and 2 below shows the results for convergent and discriminant validity:

Table 1: Convergent Validity

\begin{tabular}{ccccc}
\hline \hline Constructs & Items & Loadings & Ave & Cr \\
\hline Superv. Support & C1 & 0.881198 & 0.732849 & 0.961016 \\
& C2 & 0.876751 & & \\
C3 & 0.808298 & & \\
C4 & 0.881198 & & \\
& C5 & 0.876751 & & \\
C6 & 0.808298 & & \\
& C7 & 0.881198 & & \\
& C8 & 0.876751 & & \\
Peer Support & D1 & 0.808298 & & \\
& D2 & 0.868025 & & \\
& D3 & 0.889566 & & \\
& D4 & 0.868025 & & \\
& D5 & 0.889566 & & \\
& D6 & 0.868025 & & \\
\hline Trans. Mot & E1 & 0.889566 & & \\
& E2 & 0.7281049 & & \\
& E3 & 0.839736 & & \\
& E4 & 0.848716 & & \\
& E5 & 0.809393 & & \\
& E6 & 0.793699 & & \\
\hline \hline
\end{tabular}

Source: Field survey

Note: $\mathrm{CR}=$ Composite Reliability, AVE = Average Variance Extracted

Table 2: Discriminant Validity

\begin{tabular}{ccccccc}
\hline \hline Constructs & O C & J I & S S & P S & T M & ToT \\
\hline S S & 0.600 & 0.795 & $\mathbf{0 . 8 5 6}$ & & & \\
P S & 0.237 & 0.461 & 0.494 & $\mathbf{0 . 8 7 8}$ & & \\
T M & 0.500 & 0.896 & 0.838 & 0.440 & $\mathbf{0 . 7 3 8}$ & \\
ToT & 0.573 & 0.731 & 0.77 & 0.325 & 0.722 & $\mathbf{0 . 8 2 2}$ \\
\hline \hline
\end{tabular}

Source: Field survey

The objective of this study was to investigate the mediating role of transfer motivation in the relationship between supervisor support and peer support on transfer of training. The variables under investigation were measured on the ordinal scale level of statistical measures. 


\section{$H_{a} 1$ : Transfer Motivation mediates the effect of Supervisor Support on Transfer of Training}

The result of the PLS-SEM bootstrap for testing the mediation role of transfer motivation on supervisor support in transferring training was showcased in Table 3, Figure 1, Figure 2, and Figure 3 below, respectively. Moreover, the result of the PLS-SEM bootstrap showed that the Beta value for the relationships between supervisor support and transfer of training was $\beta=0.831$. However, the values of Beta, $\mathrm{T}$-statistics and $\mathrm{P}$ values for the relationships between supervisor support, transfer motivation and transfer of training was $\beta=0.503 ; \mathrm{t}=10.157, \mathrm{p}=0.000(\mathrm{p}<0.05)$. Therefore, all the values for such relationship exceeded 1.96 at 0.05 confidence levels using two tail tests. Furthermore, the level of mediation strength indicated that when transfer motivation was included $(\beta=0.503, \mathrm{p}=0.000)$ there was a positive mediation relationship between supervisor support and transfer of training constructs. However, when transfer motivation was not included into the analysis $(\beta=0.831, p=0.000)$, the result was found to be significantly correlated with transfer of training. Therefore, the strength of the relationship between supervisor support and transfer of training has been decreased after the inclusion of transfer motivation, but the values of T-Statistics and Sobel Test Statistics still remain significant $(\mathrm{t}=10.157$; Sobel Test Statistics $=4.935 ; \mathrm{p}=0.000)$ which are all greater than 1.96. Hence, statistically, this study revealed that transfer motivation partially mediates the relationship between supervisor support and transfer of training in the organization. Considering the above statistical findings, Hypothesis $\mathrm{H}_{\mathrm{a}} 1$ was supported. Besides, the results connote that the extent of effort, direction, persistence, and intensity towards employees' primary sources of interactive support from supervisors would positively affect their level of training transfer in the organization. Similarly, the result revealed that the degree of support, assistance, and encouragements, from supervisors and peers may perhaps bring about improved training intention, desire and persistent efforts among employees, which in turn results in enhanced application of the knowledge on the jobs.

\section{$H_{a} 2$ : Transfer Motivation mediates the effect of Peer Support on Transfer of Training}

The PLS-SEM bootstrapped result exposed that the Beta value for the relationships between peer support and transfer of training was $\beta=0.105, p=0.000$. Nonetheless, the values of Beta, T-statistics and $\mathrm{P}$ values for the relationships between peer support, transfer motivation and transfer of training was $\beta=0.057 ; t=1.967, p=0.000(p<0.05)$. Therefore, all the values for such relationships contains an absolute values $\geq 1.96$ at 0.05 confidence levels using two tail test or $\geq 1.64$ at 0.05 significance level using onetail tests. In addition, for the strength of the mediator, the inclusion of transfer motivation $(\beta=0.057$, $\mathrm{p}=0.000$ ) indicated that there was a positive mediation relationship between peer support and transfer of training. Nonetheless, prior to the inclusion of transfer motivation into the analysis $(\beta=0.105$, $\mathrm{p}=0.000$ ), the result was found to be significantly correlated with training transfer. Impliedly, the strength between peer support and transfer of training has been decreased after the inclusion of transfer motivation, but the T-Statistics and Sobel Test Statistics still remain significant $(\mathrm{t}=1.967$; Sobel Test Statistics $=4.306 ; \mathrm{p}=0.000$ ) which are all greater than 1.64 at 0.05 significance level using one-tail test. Hence, statistically, this study revealed that transfer motivation partially mediates the relationship between peer support and transfer of training in the organization. From the views of the above statistical figures, Hypothesis $\mathrm{H}_{\mathrm{a}} 2$ was failed to reject. Supplement to that, the results exhibited that the extent of effort, direction, persistence, and intensity towards employees' support from peers would positively affect transfer of training in the organization. In a similar vein, the result disclosed the degree of reinforcement, encouragements and support from peers to use the learned knowledge and skills on the job may perhaps bring about improved training transfer motivation among employees, which in turn leads to enhanced application of the learned training knowledge and skills on the job. 
Table 3: Result of The Mediating Role of Transfer Motivation on Work Environment in Transferring Training

\begin{tabular}{ccc}
\hline \hline Paths & $\begin{array}{c}\text { Supervisor Support } \rightarrow \\
\text { Transfer Motivation } \rightarrow \\
\text { Transfer of Training }\end{array}$ & $\begin{array}{c}\text { Peer Support } \rightarrow \\
\text { Transfer Motivation } \rightarrow \\
\text { Transfer of Training }\end{array}$ \\
\hline Direct without Mediation & 0.831 & 0.105 \\
Direct with Mediation & 0.503 & 0.057 \\
Independent Variable to Mediator (Beta $(\beta))$ & 0.906 & 0.122 \\
Mediator to Dependent Variable (Beta $(\beta))$ & 0.359 & 0.359 \\
Independent Variable to Mediator (Standard Error) & 0.008 & 0.013 \\
Mediator to Dependent Variable (Standard Error) & 0.073 & 0.072 \\
T-Statistics (T-value) & $10.157 * *$ & $1.967 *$ \\
Sobel Test Statistics & 4.935 & 4.306 \\
Two Tailed Probability (P-value) & 0.000 & 0.000 \\
\hline \hline
\end{tabular}

Source: Field survey

Note: Values are calculated using PLS bootstrapping routine with 603 cases and 5000 samples. Level of significance** $\mathrm{p}<0.05$ (2tailed). ${ }^{*} \mathrm{p}<0.05$ (1-tailed)

Figure 1: PLS-SEM Algorithm for The Direct Relationship of Supervisor Support, Peer Support and Transfer of Training

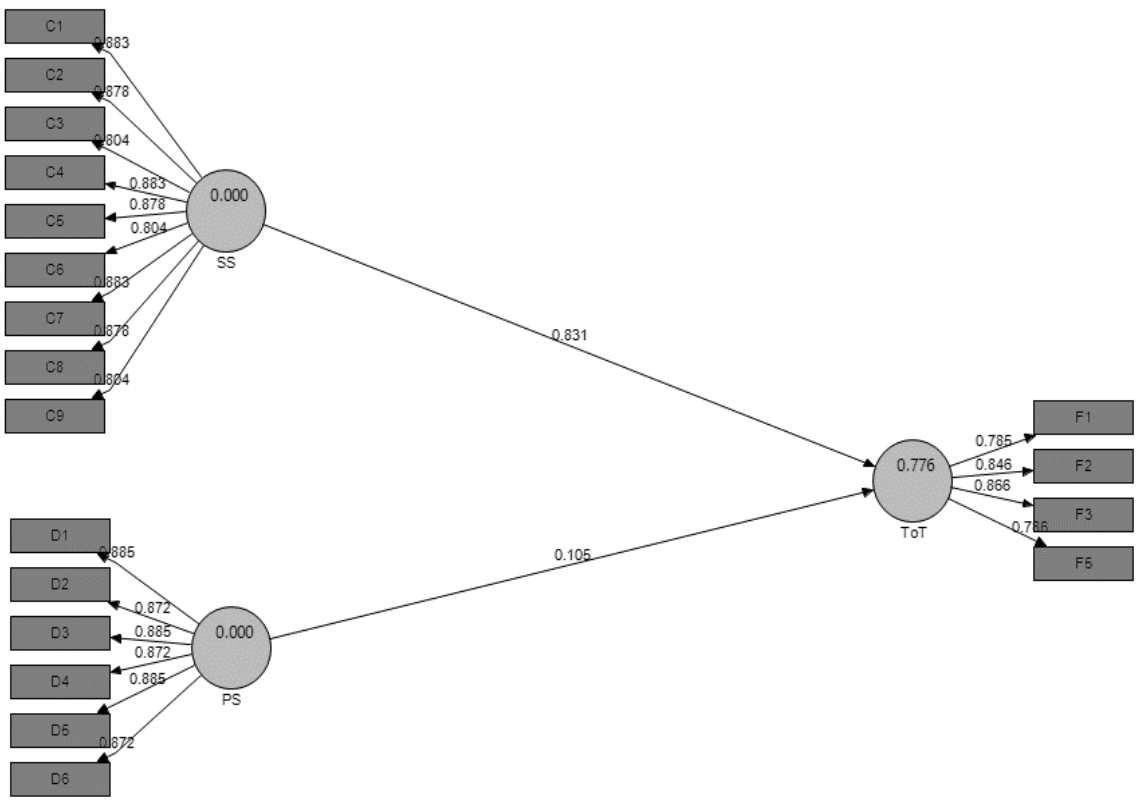


Figure 2: PLS-SEM Algorithm for The Indirect Mediating Role of Transfer Motivation on Supervisor Support, Peer Support and Transfer of Training

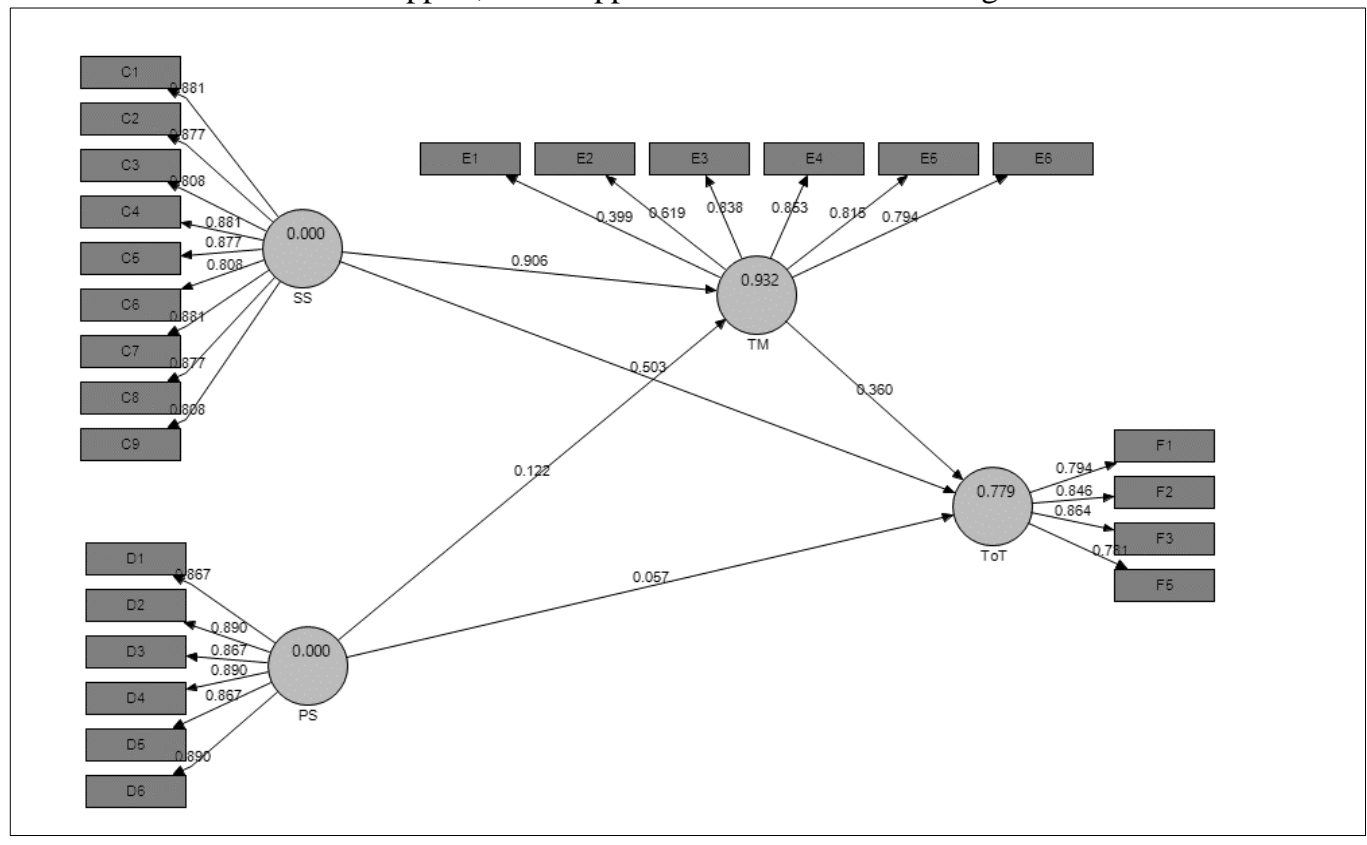

Figure 3: PLS-SEM Bootstrap for The Indirect Mediating Role of Transfer Motivation on Supervisor Support, Peer Support and Transfer of Training

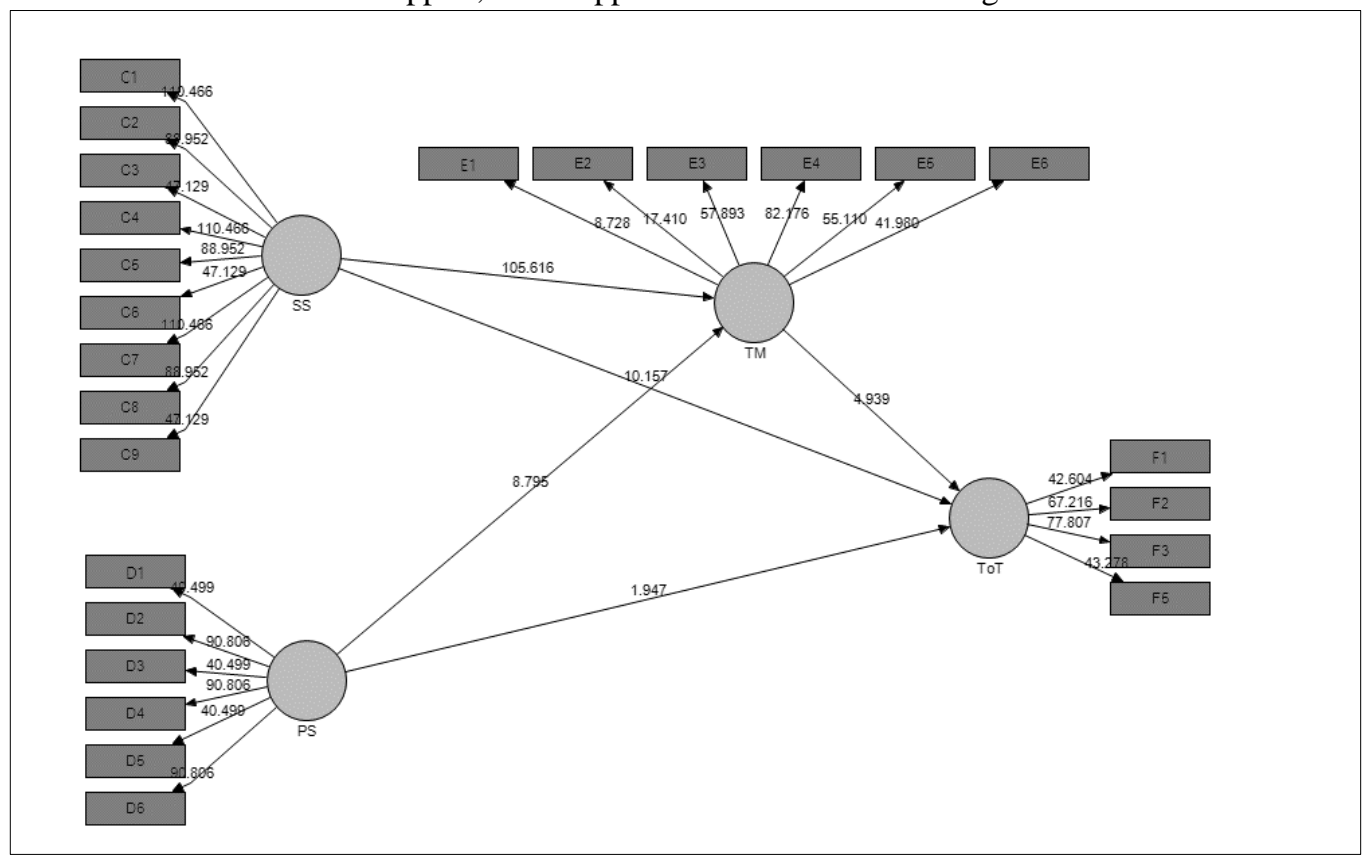




\section{DISCUSSION}

The findings are consistent with the Bandura's theory which viewed support or encouragement as a predominant change in human being through the effect of human thought (Olson \& Hergenhahn, 2009). Cognitive support enables human beings to find solutions to their challenges via thoughts rather than physical movement. Hence, human mind is a great agent that allows persons to understand and deal effectively with their work environment as it encompasses large treasure of knowledge in a form of experiences (Bigge \& Shermis, 2004). By supporting their behaviors, people have the idea of new system of behaviors that is attached by a recognized situation in which the new system may be displayed. Since most external factors that affect behavior through the combined cognitive processes are factors that heavily organize, identifies, and give meanings to which environmental information will be observed in future applications.

Additionally, support through supervisor or peer who is originated from motivation processes is more powerful than contiguity of activities. The total effect of motivation reinforces as soon as the requisite responses were emitted. This is a tricky process that produced mediocre results in an ethically pleasurable ways (Bigge \& Shermis, 2004). Social cognitive learning theory describes how a combination of social and personal competencies can be evolved from the elements of work environment that emerge. Cognitive transfer of knowledge is promoted through modelling and performance feedback. The nature of transfer of training shows several ways of conveying knowledge about behavior and ascertained relationship between personal characteristics and events in the work environment. Implications served as an uncompounded means (support) of informing people what they ought to do so as to reveal certain outcomes (training transfer) through observing the several results of their actions.

Training empowers employees to enhance their employability, upgrade flexibility, enhance work assurance and gainfulness, and help organizations build the employees' levels of output, lower expenses, enhance efficiency, lower absenteeism rates, decrease material waste, and decrease injury rates (Lamastro, 1999). More so, in order to achieve an effective transfer of training, a supportive and motivated work environment is important for trained employees to maintain and improve their knowledge and skills over time. Therefore, employees must experience encouragement and reward for mastering and using new learned skills and knowledge from supervisors. Applying new skills need to take time and more practice to become a part of an employee's strength and capability (Gitonga, 2006). Practice in the workplace setting shall occur with coaching by the supervisors and peers through training.

This finding, however, is in line with the prior empirical studies of Tracey et al. (2001) who uncovered that employee's level of transfer motivation will affect his or her training transfer. It is confirmed that specific factor of training transfer motivation influences training results, Hence, it is a vital indicator variable in correlating trainee characteristics to training transfer (Egan et al., 2004; Ismail \& Bongogoh, 2007). However, the training program managers who are assigned with setting the motivation of employees and training design would be responsible in ensuring that the gained knowledge and skills are transferred back to the job. This assertion is in congruent with its probable impact on effectiveness of training.

In a nutshell, support that begins from the supervisor and peers by way of transfer motivation may have a punctuated or verbose character with transfer of training and periodic checks of progress. It is contended that the higher level of perceived transfer motivation of every employee would lead them to transfer the learned skills and knowledge which also increases their performance level. Hence, in order for employees to transfer the skills and knowledge learned, trainee must have elements of transfer motivation. That is to say, transfer motivation is the trainees' desire to apply and use on their jobs the knowledge and skills that have been delivered in training programs. 


\section{CONCLUSION AND IMPLICATIONS}

This research implied that the provision of supervisor and peer support could enhance transfer of training, but, these might not ultimately motivate employees to transfer training in different work setting. Hence, transfer motivation is crucial. Without proper transfer motivation from the employers it is difficult to motivate employees to transfer as well utilize the knowledge and skills learned onto the job. It can be concluded that the selected factors of work environment through transfer motivation were the significant determinants of training transfer among staff of State Universal Basic Education Board, Bauchi, Nigeria. Therefore, it is imperative to give full concentration to these factors in ensuring transfer of training KSAs on the job, especially in terms of lower levels transfer of training behaviors that is persistently exhibited by employees of Bauchi State, Nigeria. More so, the model of process of training transfer developed by Baldwin and Ford (1988) focuses on some key predictor elements of trainee characteristics, work or training design, work environment, learning and retention, generalization and maintenance and transfer of training itself while ignoring and omitting employee motivational job attitude predictor factors which is among the most vital ingredients on promoting and achieving the overall goals and objective of an organization (Cheng, 2006; Mani et al., 2006).

This study has empirically contributed to the body of knowledge by assessing the supervisor support and peer support factors of transfer motivation, and transfer of training. Highly transfer motivated employees have better and improved productivity in the organization as compared with low transfer motivated employees. Employees on their personal interest perceived to be highly motivated to transfer and make some improvements in their jobs. So, this will result in high performance in their daily works. Perhaps, highly motivated employees who are encouraged to carry out their task are more likely to view their organization as the only means to obtain future benefits. However, this will enhance the competitive capabilities of the organizations in actively competing and surviving in the market environment. As a result of this, the level of transfer motivation and transfer of training might be affected in State Universal Basic Education Board, Bauchi State, Nigeria. In spite of these inadequacies, this study has established that the concept of transfer motivation has been efficaciously applied in the models of transfer of training.

\section{REFERENCES}

Abdullah, H. (2009). Training needs assessment and analysis: A case of Malaysian manufacturing firms. European Journal of Scientific Research, 37(3), 351-360.

Adair, J. (1988). The effective supervisor. London: The Industrial Society.

Aguinis, H., \& Kraiger, K. (2009). Benefits of training and development for individuals and teams, organizations, and society. Annual Review of Psychology, 60(5), 451-474.

Akinbobola, O. I. (2011). Conflict in human capital relationships: The impact of job satisfaction on job involvement in a workplace. International Journal of Social Science and Humanity, 1(2), 92-98.

Baldwin, T. T., \& Ford, J. K. (1988). Transfer of training: A review and directions for future research. Personnel Psychology, 41(2), 63-105.

Barclay, D., Higgins, C., \& Thompson, R. (1995). The partial least squares (PLS) approach to causal modelling. Technology Studies, 2(4), 285-323.

Bhatti, M. A., \& Hoe, C. H. (2012). Resolving the past conflict: Role of peer and supervisor support in training effectiveness. International Journal of Business and Behavioural Sciences, 2(7), 32-38.

Bigge, M. L., \& Shermis, S. S. (2004). Learning theories for teachers $\left(6^{\text {th }}\right.$ Ed.). USA: Pearson Education Inc. 
Bjerregaard, K., Haslam, S. A., \& Morton, T. (2016). How identification facilitates effective learning: the evaluation of generic versus localized professionalization training. International Journal of Training and Development, 20(1), 17-37.

Bulut, C., \& Culha, O. (2010). The effects of organizational training on organizational commitment. International Journal of Training and Development, 14(4), 309-322.

Burke, L. A., \& Hutchins, H. M. (2007). Training transfer: An integrative literature review. Human Resource Development Review, 6(3), 263-296.

Chang, J. C., \& Chiang, T. C. (2011). The effects of trainee characteristics on transfer of training in pre-training stage. Paper presented at the 2011 International Conference on Management and Service Science, Wuhan, China.

Cheng, H. (2006). A review of transfer of training studies in the past decade. Personnel Review, 68(2), 245-261.

Chiaburu, D. S., \& Lindsay, D. R. (2008). Can do or will do? The importance of self-efficacy and instrumentality for training transfer. Human Resource Development International, 11(2), 199-206.

Chin, W. W. (2010). How to write up and report PLS analyses. Handbook of partial least squares. New York: Springer Verlag.

Chiou, H., Lee, Y., \& Purnomo, S. H. (2010). The influences transfer of training on relationship between knowledge characteristic of work design model and outcomes. International Journal of Innovation, Management and Technology, 1(2), 116-124.

Combs, G., Luthans, F., \& Griffith, J. (2009). Learning motivation and transfer of human capital development: Implications for psychological capital. Journal of Psychology Management, 42(3), 324-348.

Creswell, J. W. (2008). Educational research: planning, conducting and evaluating quantitative and qualitative research. New Jersey: Pearson Prentice Hall.

Danielson, C. C., \& Wiggenhorn, W. (2003). The Strategic Challenge for Transfer: Chief Learning Officers Speak Out. In E. F. Holton \& T. T. Baldwin (Eds.), Improving learning transfer in organizations (pp. 16-38). San Francisco: Jossey-Bass.

Davis, D. (1996). Businees research for decision making. Belmont. CA: Duxbury Press

Egan, T. M., Yang, B., \& Bartlett, K. R. (2004). The effects of organizational learning culture and job satisfaction on motivation to transfer learning and turnover intention. Human Resource Development Quarterly, 15(3), 279-301.

Facteau, J. D., Dobbins, G. H., Russell, J. E. A., Ladd, R. T., \& Kudisch, J. D. (1995). The influenceof general perceptions of the training environment on pretraining motivation and perceived training transfer. Journal of Management, 21(1), 1-25.

Foxon, M. (1997). The influence of motivation to transfer, action planning, and manager support on the transfer process. Performance Improvement Quarterly, 10(2), 42-63.

Gitonga, J. W. (2006). Work environment factors influencing the transfer of learning for online learners. Illinois: University Press.

Guerrazzi, M. (2016). The effect of training on Italian firms' productivity: microeconomic and macroeconomic perspectives. International Journal of Training and Development, 20(1), 38-57.

Hair, J. F., Black, B., Babin, B., Anderson, R. E., \& Tatham, R. L. (2006). Multivariate data analysis $\left(6^{\text {th }}\right.$ Ed.). Upper saddle River, NJ: Prentice-Hall.

Henseler, J., \& Sarstedt, M. (2013). Goodness-of-fit indices for partial least square path modelling. Computational Statistics, 28(2), 565-580.

Holton, E. F., \& Bates, R. A. (2000). An exploratory study of learning transfer systems among starrated hotels in Hainan, China. International Journal of Training and Development, 3(2), 442-463.

Howardson, G. N., \& Behrend, T. S. (2015). The relative importance of specific self-efficacy sources in pretraining self-efficacy beliefs. International Journal of Training and Development, 19(4), 233-252. 
Hua, N. K., \& Ahmad, R. (2011). The impact of the supervisor's role in training programmes on the transfer of training: A case study in four east Malaysian local governments (Unpublished doctoral dissertation). Universiti Kebangsaan Malaysia, Malaysia.

Ismail, A., \& Bongogoh, S. (2007). The supervisor's role in training programmes: An empirical study in one city based local authority in Sarawak, Malaysia. UNITAR e-journal, 3(2), 60-71.

Jarvis, P., Holford, J., \& Griffin, C. (2006). The theory and practice of learning. Oxon: Routledge Falmer.

Lamastro, V. (1999). Commitment and perceived organizational support. National Forum of Applied Educational Research Journal, 12(3), 1-13.

Jehanzeb, K., Rasheed, A., \& Rasheed, M. F. (2013). Organizational commitment and turnover intentions: impact of employee's training in private sector of Saudi Arabia. International Journal of Business and Management, 8(8), 79-90.

Kanungo, R. N. (1982). Measurement of job and work involvement. Journal of Applied Psychology, 67(3), 341-349.

Kirwan, C., \& Birchall, D. (2006). Transfer of learning from management development programmes: testing the Holton model. International Journal of Training and Development, 10(4), 252-268.

Krejcie, R. V., \& Morgan, D. W. (1970). Determining sample size for research activities. Educational and Psychological Measurement. 30(3), 607-610.

Lancaster, S., DiMilia, L., \& Cameron, R. (2013). Supervisor behaviours that facilitate training transfer. Journal of Workplace Learning, 25(1), 6-22.

Ling, O. A., Woon, P. H., \& Ven, K. H. (2006). The relationship between work environment factors and transfer of training among plantation workers. Jurnal Kemanusiaan, 13(6), 345-361.

Mani, S. A., John, J., Ping, W. Y., \& Ismail, N. M. (2006). Knowledge, attitude and practice towards its production in Malaysia. Intechopen, 2(1), 3-19.

Massman, A. J. (2012). Improving third generation learning : the effects of peer feedback training on quality feedback, trainee characteristics, and performance (Doctoral dissertation). Michigan State University, Michigan.

Moldjord, C., \& Hybertsen, I. D. (2015). Training reflective processes in military aircrews through holistic debriefing: the importance of facilitator skills and development of trust. International Journal of Training and Development, 19(4), 287-300.

Nijman, D. J. M., Nijhof, W. J., Wognum, A. A. M., \& Veldkamp, B. P. (2006). Exploring differential effects of supervisor support on transfer of training. Journal of European Industrial Training, 30(7), 529-549.

Nikandrou, I., Brinia, V., \& Bereri, E. (2009). Trainee perceptions of training transfer: An empirical analysis. Journal of European Industrial Training, 33(3), 255-270.

Noe, R. A. (1986). Trainees' attributes and attitudes, neglected influences on training effectiveness. Academy of Management Journal, 11(4), 736-749.

Noe, R. A., \& Schmitt, N. (1986). The influence of trainee attitudes on training effectiveness: Test of a model. Personnel Psychology, 39(2), 497-523.

Olson, M. H., \& Hergenhahn, B. R. (2009). An introduction to theories of leaning ( $8^{\text {th }}$ Ed.). Hong Kong: Pearson Education North Asia Ltd.

Petty, G. C., Lim, D. H., \& Zulauf, J. (2003). Training transfer between cd-rom based instruction and traditional classroom instruction. The Journal of Technology Studies, 1(1), 48-56.

Raliphada, N., Coetzee, J., \& Ukpere, W. I. (2014). Organisational factors affecting learning transfer in the south african public service. Mediterranean Journal of Social Sciences, 5(2), 743-754.

Ripley, D. E. (2002). The work environment and training effectiveness: An overlooked element in human resource management instructions. Retrieved from http://www.wesga.edu/-bquest/2002

Sekaran, U. \& Bougie, R. (2010). Research methods for business. A skill building approach (5 ${ }^{\text {th }}$ ed.). UK: John Willey. 
Suleiman, W., Dassanayake, M. S., Othman, A. E. A., \& Ekhsan, A. (2015). A review of essentials of training transfer in organizations: HR perspective. Science International, 27(1), 407-410.

Sverke, M., \& Hellgren, J. (2002). The nature of job insecurity: Understanding employment uncertainty on the brink of a new millennium. Applied Psychology, 51(1), 23-42.

Thory, K. (2016). Developing meaningfulness at work through emotional intelligence training. International Journal of Training and Development, 20(1), 58-77.

Tracey, J. G., Hinkin, T. R., Tannenbaum, S., \& Mathieu, J. E. (2001). The influence of individual characteristics and the work environment on varying levels of training outcomes. Human Resource Development Quarterly, 12(7), 5-23.

Van der locht, M., van Dam, K., \& Chiaburu, D. S. (2013). Getting the most of management training: the role of identical elements for training transfer. Personnel Review, 42(4), 422-439.

Wei, T. A., Cordery, J., \& Gamble, J. (2016). Returning the favor: positive employee responses to supervisor and peer support for training transfer. International Journal of Training and Development, 20(1), 1-16. 